\title{
O percurso escolar dos imigrantes italianos e alemães na Serra dos Tapes (Pelotas/RS, 1920-1950): similitudes e particularidades
}

\author{
The educational history of Italian and German immigrants in the Serra dos Tapes \\ (Pelotas/RS, 1920-1950): similarities and particularities \\ El itinerario escolar de los inmigrantes italianos y alemanes en la Serra dos Tapes \\ (Pelotas/RS - 1920 - 1950): similitudes y particularidades
}

\author{
Renata Brião de Castro \\ Universidade Federal de Pelotas (Brasil) \\ https://orcid.org/0000-0002-5724-6621 \\ http://lattes.cnpq.br/8866766022973381 \\ renatab.castro@gmail.com \\ Patrícia Weiduschadt \\ Universidade Federal de Pelotas (Brasil) \\ https://orcid.org/0000-0001-6804-7591 \\ http://lattes.cnpq.br/0643205535014525 \\ prweidus@gmail.com
}

\section{RESUMO}

Neste artigo analisam-se as memórias da trajetória escolar dos descendentes de imigrantes italianos e de alemães na região da Serra dos Tapes. Para isso, as fontes de pesquisa estão constituídas por 32 entrevistas, as quais são acervo do Museu Etnográfico da Colônia Maciel, localizado no interior do município de Pelotas (RS). Para isso, utilizam-se teorias acerca da memória coletiva, etnicidade e identidade. A metodologia empregada é a da história oral. $\mathrm{O}$ recorte temporal está estabelecido nas décadas em que os entrevistados frequentaram a escola (1920-1950). Serão abordadas as similitudes e particularidades entre os dois grupos. Em ambos os grupos se nota a importância atribuída a escolarização e a religiosidade. Nas particularidades, percebe-se que o grupo dos italianos preferiam as escolas públicas, enquanto os alemães optavam pelas comunitárias em língua alemã.

Palavras-chave: grupo étnico; escolarização; imigrantes italianos; imigrantes alemães. 


\begin{abstract}
This article analyzes school history records of Italian and German immigrant descendants in the Serra dos Tapes (Tapes Mountain Range) district. Research sources consisted of 32 interviews, which integrate the collection of the Colônia Maciel Ethnographic Museum, located in the municipality of Pelotas (RS) countryside. For such, theories on collective memory, ethnicity and identity were used. The methodology employed had an oral history focus. The timeline refers to the decades in which the interviewees attended school (19201950). Similarities and particularities between the two immigrant groups were addressed. The importance attributed to schooling and religion could be detected in both groups. As for particularities, the Italian group preferred public schools, whereas the Germans opted for community schools which taught in German.
\end{abstract}

Keywords: ethnic group; schooling; Italian immigrants; German immigrants

\title{
RESUMEN
}

En este artículo se analizan las memorias de la trayectoria escolar de los descendientes de inmigrantes italianos y de alemanes en la región de la Serra dos Tapes. Para ello, las fuentes de investigación están constituidas por 32 entrevistas, las cuales son acervo del Museo Etnográfico de la Colonia Maciel, ubicado en el interior del municipio de Pelotas (RS). Para ello, se utilizan teorías acerca de la memoria colectiva, etnicidad e identidad. La metodologia empleada es la de la historia oral. El recorte temporal está establecido en las décadas en que los entrevistados asistieron a la escuela (1920-1950). Se abordarán asimilitudes y particularidades entre los dos grupos. En ambos grupos se nota la atenuación atribuida a la escolarización y la religiosidad. En las particularidades, se percibe que el grupo de los italianos preferían las escuelas públicas, mientras que los alemanes optaban a las comunidades en lengua alemana.

Palabras clave: grupo étnico; la escolarización; inmigrantes italianos; inmigrantes alemanes. 


\section{Introdução}

O objetivo deste texto é analisar um conjunto de 32 entrevistas, as quais estão constituídas como acervo no banco de dados do Museu Etnográfico da Colônia Maciel, esse localizado na Colônia Maciel (MECOM), distrito rural do município de Pelotas (RS). A Colônia Maciel é uma localidade que foi colonizada, no final do século XIX, por imigrantes de origem italiana, pertencente a chamada Serra dos Tapes, essa região historicamente foi colonizada por diversos grupos étnicos: italianos, alemães, franceses, pomeranos. Com o andamento da pesquisa, tomou-se conhecimento do Banco de Imagens e Sons do Museu Etnográfico da Colônia Maciel, o qual possui um acervo dividido em três categorias: os objetos tridimensionais, as imagens e o acervo oral. No que tange ao acervo oral, são entrevistas coletadas na fase de implantação do referido espaço museológico, entre os anos de 2000 e 2006. O Museu foi inaugurado no ano de 2006, é fruto de um projeto de pesquisa do Laboratório de Ensino e Pesquisa em Antropologia e Arqueologia (LEPAARQ) da Universidade Federal de Pelotas. De acordo com os autores, o MECOM "visa pesquisar, difundir e preservar a história da comunidade italiana na colônia de Pelotas [...]" (PEIXOTO et al, 2008, p. 4).

Conforme Cerqueira et al (2009), as entrevistas seguiram os preceitos da história oral e foram realizadas com moradores locais, os quais conheciam a memória coletiva daquela região. Os autores seguem explicando a elaboração destas entrevistas:

[...] foram realizadas 32 entrevistas. Destas, 8 foram feitas na primeira etapa do projeto (2000 a 2002) e 24 na etapa de implantação do museu (2005). Ainda estão previstas 12 entrevistas com membros de famílias de ítalo-descendentes, naturais da colônia, que atualmente residem na zona urbana do município de Pelotas. Há que se ressaltar que em alguns casos foram realizadas duas ou mais entrevistas com a mesma pessoa, uma vez que estas tinham grande número de informações que contribuiriam com a pesquisa (CERQUEIRA et al, 2009, p. 80).

Desta forma, ao iniciar as pesquisas nesse acervo oral verificou-se que, entre os entrevistados, havia a predominância de descendentes de imigrantes italianos, seguido dos descendentes de alemães. Assim sendo, este texto busca analisar os aspectos relativos a escolarização e a educação desses dois grupos étnicos, estabelecendo algumas comparações. Ainda, busca-se abordar elementos da religiosidade presentes nesses grupos e relacionar sempre que possível com a escolarização, pois, como referido em muitos estudos, os imigrantes atribuíam importância a esses dois fatores: escola e religião. Outro aspecto analisado refere-se ao item do trabalho. As comunidades de imigrantes conferem significado ao trabalho, em suas memórias é ressaltado que as dificuldades no início da colonização foram vencidas com a força de trabalho do colono, inclusive as instituições de ensino em algumas localidades são rememoradas pelos entrevistados como fruto do trabalho coletivo das comunidades.

No que diz respeito ao recorte temporal, este não se refere a nenhum período em específico, a data em que os entrevistados, possivelmente, foram alfabetizados (1920-1950), considerando a data de nascimento destes. 


\section{Percurso teórico-metodológico}

Nesse momento será, primeiramente, explicado como foram trabalhadas as entrevistas. Um dos primeiros passos foi organizar o banco de dados do qual foram originadas as fontes para esta pesquisa, ressaltando que um banco de dados, para pouco, ou para nada, serve se não houver uma sistematização das informações. É necessário criar um sistema de classificação de acordo com a problemática que se pretende investigar. Dessa forma, organizar os dados foi a primeira tarefa. Corroborando as ideias de Certeau (1982, p. 81), afirma-se que "em história, tudo começa com o gesto de separar, de reunir, de transformar em 'documentos' certos objetos distribuídos de outra maneira. Esta nova distribuição cultural é o primeiro trabalho". Ainda de acordo como o autor:

[...] não se trata apenas fazer falar estes "imensos setores adormecidos da documentação" e dar voz a um silêncio, ou efetividade a um possível. Significa transformar alguma coisa, que tinha sua posição e seu papel, em alguma outra coisa que funciona diretamente (CERTEAU, 1982, p. 83).

Assim, apreende-se que a pesquisa faz-se com a desmontagem dos dados, para rearranjá-los de outro modo. Kuhlmann e Fernandes (2014), ao explicitar a construção de banco de dados relativos a periódicos, observam que para a compreensão dos periódicos de forma mais profunda, foram necessários o agrupamento e a classificação das informações. Embora os autores se refiram a fontes diferenciadas destas aqui, no caso deles, a publicação de um periódico e desta pesquisa as fontes orais, é possível relacionar a necessidade da organização dos dados, ainda:

A utilização das técnicas atuais de informação leva o historiador a separar aquilo que, em seu trabalho, até hoje esteve ligado: a construção de objetos de pesquisa e, portanto, das unidades de compreensão; a acumulação dos dados [...] e sua arrumação em lugares onde possam ser classificados e deslocados; a exploração é viabilizada através das diversas operações de que este material é susceptível (CERTEAU, 1982, p. 85).

Um acervo oral constituído é possível de ser trabalhado por vários ângulos e por diversos campos de conhecimento, haja vista que a orientação da abordagem está relacionada com as perguntas do pesquisador para a fonte. Não se está a dizer que tudo poderá ser feito sem critérios e rigor com todos os documentos, apenas pontua-se a possibilidade do uso de acervos orais, bem como a importância da constituição destes para pesquisas futuras. Nessa linha, Grazziotin e Almeida (2012) teorizam sobre documentos orais:

[...] ela permite a aproximação de verdades que ser quer produzir sobre o vivido. E guarda o mérito de trazer á tona nuances do passado, que podem estar esquecidas e que, por vezes, se encontram inatingíveis em outras formas de documentação, além de dar visibilidade aos sujeitos na construção da história [...] (GRAZZIOTIN; ALMEIDA, 2012, p. 36-37).

Voldman (2006) faz uma diferenciação entre arquivo e fonte oral. No primeiro estariam os documentos produzidos por pesquisadores e guardados para investigações futuras. Esse seria o objetivo da produção dessas narrativas, quer seja, constituir um banco de dados. Por sua vez, a fonte oral é aquela produzida pelo historiador para a sua própria pesquisa. Na perspectiva dessa autora, podem-se enquadrar essas entrevistas do MECOM como arquivos orais. 
Grazziotin e Almeida (2012, p. 42), ao tratar do tema, escrevem que o acervo oral não se caracteriza por um assunto em específico, mas, sim, possui vários e, por isso, pode ser examinado por diferentes ângulos. Neste ínterim, as autoras se questionam: "Como garimpar nessa profusão de memórias aquelas que interessam? Como o investigador poderá separar e reagrupar as memórias de acordo com os objetivos da pesquisa a que se propõe?". Com essas questões, disserta-se acerca do modo como utilizou-se este acervo oral. As entrevistas encontravam-se transcritas, foram usadas as transcrições e não o áudio. Algumas questões nortearam a presente pesquisa, tais como: o que é possível analisar a partir desse conjunto? Quais categorias podem ser criadas e agrupadas? O que utilizar e o que não utilizar? Por esse ângulo foi perceptível que antes de qualquer análise mais aprofundada era necessário conhecer, inventariar as informações e posteriormente pensar categorizações e possibilidades de análise

Grazziotin e Almeida (2012, p. 43) assinalam que nos acervos orais, por não estarem na temática central de uma pesquisa em específico, é comum as categorias emergirem, havendo um "elemento surpresa". O pesquisador, ao mesmo tempo em que perde relativamente o controle sobre a pauta interessada, vai construindo o processo de acordo com as lembranças e os esquecimentos dos sujeitos.

Grazziotin e Almeida (2012) escrevem acerca das suas investigações, nas quais fazem uso de entrevistas realizadas por outros pesquisadores e, dessa forma, teorizam sobre as diferenças em relação aos depoimentos coletadas no contexto de uma pesquisa própria.

Assim, ao contrário das entrevistas elaboradas com o fim único de responder às questões específicas de um determinado pesquisador, a forma da história oral dessa pesquisa vem num sentido muito mais de suscitar questões. Antes de responder a questões, as memórias colhidas têm mais a ver com o que o sujeito tinha para contar e não em função de entrevistas estruturadas com um fio condutor definido, da mesma forma como um documento escrito não existe com o propósito de servir a um historiador (GRAZZIOTIN; ALMEIDA, 2012, p. 68).

Percebe-se, a partir dessas discussões, que os acervos orais possibilitam servir a mais de um pesquisador e, por isso, as memórias têm temas variados, alargados para além do que o historiador busca ou para além do que se constrói nas suas entrevistas. Sendo assim, organizou-se em oito tópicos o que se pretendia pontuar nessas entrevistas.

A partir das pesquisas de Grazziotin e Almeida (2012), as quais explicam como trabalharam com entrevistas que são acervos e como organizaram os dados em tabelas e categorias, foi pensado como seriam sistematizadas as narrativas desta pesquisa.

Desta forma, foram criadas duas tabelas. A primeira teve o objetivo de visualizar o todo, ou seja, foram colocadas as seguintes informações: número da entrevista, nome, data e local da entrevista, data de nascimento, escolarização/escola e descendência (etnia).

A segunda tabela consistiu em organizar, de fato, os dados, o que havia em cada entrevista de significativo para esta pesquisa. Assim, foram construídas oito categorias: imigração; escolarização; Escola Garibaldi/professor José Rodeghiero ${ }^{1}$; Nacionalização-língua; nacionalização do ensino; valorização da educação, italianidade; estrada de ferro. Assim, construiu-se um quadro com todas as categorias, bem como com todos os trechos de entrevistas referentes a essas categorias. É necessário pontuar que essa categorização foi realizada com base na problematização central deste trabalho, são possíveis outros arranjos e planejamentos

\footnotetext{
${ }^{1}$ Esta categoria "Escola Garibaldi/professor José Rodeghiero" foi criada pelo fato dissertação de mestrado, da qual é oriunda esse artigo, ter como objetivo central essa escola e esse professor.
} 
para esse mesmo material, pois como afirma Luchese (2014), são as perguntas do pesquisador e a subjetividade deste que estarão presentes no momento de analisar os dados.

Para além dessas oito categorias, foram também organizados os trechos das narrativas, nas quais é possível perceber rememorações acerca da religiosidade dos grupos étnicos e também a valorização do trabalho. A partir da primeira tabela foi possível visualizar quais etnias estavam presentes no banco de dados. Essa tabela além da descendência do entrevistado, também reuniu dados referentes a localidade onde foram realizadas as entrevistas, a residência dos narradores, a idade desses, onde haviam estudados, seu percurso escolar, a relação com a religiosidade e a valorização do trabalho por parte dos entrevistados. Com os dados organizados foi possível observar quantos entrevistados de cada etnia havia no conjunto das narrativas, assim em um os 30 narradores estão assim distribuídos: ${ }^{2} 18$ italianos; 7 alemães; 1 belga; 1 francês; em 3 das narrativas não foi possível perceber a descendência. Foi possível notar que os entrevistados eram de faixa etária diferentes. Dessa forma, organizou-se por décadas a data de nascimento dos entrevistados. Em algumas não foi possível identificar a data de nascimento, nas demais: um entrevistado na década de 1910; seis na década de 1920; cinco em 1930; três na década de 1940 e um na de 1950.

A partir desta organização foi possível analisar esses documentos dentro de uma problemática de pesquisa. Conforme Barros (2011), um problema de pesquisa corresponde a uma questão dentro de um tema. Assim, a indagação que se propõe aqui é: apontar quais são as diferenças e similitudes entre o percurso escolar dos descendentes de italianos e alemães no contexto analisado.

\section{As memórias dos descendentes dos imigrantes italianos e dos alemães}

Após o percurso teórico e metodológico, que deu sustentação a pesquisa, passa-se a analisar as fontes. O próximo passo foi verificar onde estudaram cada um dos entrevistados, nesse momento utilizando, especificamente, as narrativas dos italianos e dos alemães. Antes de analisar os dados, algumas explicações fazem-se necessárias. Primeiramente é oportuno registrar que a localidade, onde foram realizadas as entrevistadas, (Colônia Maciel) está situada em uma área de imigração italiana, majoritariamente. Fato que explica o maior número de entrevistados serem dessa etnia, pois a maioria dos entrevistados era da Colônia Maciel, local onde mais tarde foi criado o Museu Etnográfico da Colônia Maciel, tendo como um dos seus objetivos preservar a memória da imigração italiana naquele espaço. Entretanto, é uma região onde também se encontram descendentes de imigrantes alemães e franceses. Toda essa região, chamada de Serra dos Tapes, foi colonizada no final do século XIX por imigrantes emigrados da Europa. Há algumas colônias que receberam mais italianos, outras mais alemães e, também, franceses. Outro aspecto relevante de ser mencionado refere-se a escola da localidade. Na Colônia Maciel, desde o ano de 1929 existe a Escola Garibaldi, uma escola pública municipal que recebeu, em um primeiro momento, muitos alunos de descendência italiana ${ }^{3}$. Em conversas com a comunidade e professores da escola, alguns relembram que seus familiares não estudaram na Garibaldi porque eram de origem alemã, sendo assim estudavam em um colégio específico para os alemães. Nesse momento, percebem-se questões étnicas envolvidas.

Por se tratar de uma investigação onde estão permeadas questões identitárias étnicas, é necessário explicar o que está sendo entendido como identidade e etnicidade. Emprega-se a noção de identidade presente em Hall (2014), na qual a identidade é concebida como algo construído histórico e socialmente. A maioria dos grupos imigratórios acredita que a terra

\footnotetext{
${ }^{2}$ É necessário explicar que são 32 entrevistadas, entretanto são 30 narradores, visto que foi realizado mais de uma entrevistada com um dos entrevistados.

${ }^{3}$ A Escola Garibaldi durante os anos de 1928 a 1950 foi objeto da dissertação de Castro (2017).
} 
natal ainda permanece inalterada, partilham valores essencialistas, ou seja, acreditam em valores essencialmente italianos, os quais já foram modificados desde o século XIX. Woodward (2014) escreve sobre as visões essencialista e não-essencialista. A primeira, conforme essa autora, não se altera com o tempo, já a visão não-essencialista foca nas diferenças, assim como no que é comum entre os grupos e as mudanças ocorridas ao longo do tempo (WOODWARD, 2014). Nesse momento, é importante pensar sobre as comunidades imaginadas, a noção da identidade nacional depende da compreensão que temos dela (ANDERSON, 2008). Os grupos de imigrantes têm uma "imaginação" acerca da terra natal e a identidade étnica passa por essa crença. $\mathrm{O}$ ser italiano ou o ser alemão em terras estrangeiras é ressaltado pelos narradores das entrevistas analisadas, inclusive ao se referir as escolas em que estudaram, em alguns momentos, consegue-se perceber que os entrevistados buscam diferenciar as escolas que cada um dos grupos étnicos estudava, isso perpassa por questões de origem religiosas também.

Ainda é possível utilizar Hobsbawn e Ranger (2012) com o conceito da invenção das tradições. As comunidades de imigrantes ao chegar ao Brasil reinventam tradições, para os autores:

Não nos cabe analisar até que ponto as novas tradições podem lançar mão de velhos elementos, até que ponto elas podem ser forçadas a inventar novos acessórios ou linguagens, ou a ampliar o velho vocabulário simbólico. Naturalmente, muitas instituições políticas, movimentos ideológicos e grupos - inclusive o nacionalismo - sem antecessores tornaram necessária a invenção de uma continuidade histórica real seja pela lenda [...] ou pela invenção [...] (HOBSBAWM e RANGER, 2012, p. 14).

Além disso, para pensar em grupos étnicos e etnicidade apoia-se em Poutignat e Streifffenart (2011), para os autores:

Assim como não se pressupõem uma real comunidade de origem, os grupos étnicos também não pressupõem uma real atividade comunitária. Eles existem apenas pela crença subjetiva que têm seus membros de formar uma comunidade e pelo sentimento de honra social compartilhado por todos os que alimentam tal crença [...] (POUTIGNAT; STREIFF-FENART, 2011, p. 38).

Assim, compreende-se, a partir dos autores, que mais do que os aspectos físicos e biológicos da comunidade de origem, os grupos étnicos são, também, formados por compartilharem aspectos em comum, outrossim a crença na comunidade de origem mostra-se importante na consolidação das memórias. Nas fontes analisadas percebem-se esses aspectos quando os entrevistados rememoram, por exemplo, que são italianos e alguns costumes são típicos desse grupo. A identidade étnica é outra variável:

A identidade étnica (a crença na vida em comum étnica) constrói-se a partir da diferença. A atração entre aqueles que se sentem como de uma mesma espécie é indissociável da repulsa diante daqueles que são percebidos como estrangeiros. Esta ideia implica que não é o isolamento que cria a consciência de pertença, mas ao contrário, a comunicação das diferenças das quais os indivíduos se apropriam para estabelecer fronteiras étnicas (POUTIGNAT; STREIFF-FENART, 2011, p. 41). 
A identidade, e sobretudo, a étnica estabelece-se a partir da diferença (WOODWARD, 2014). É a partir do outro que são demarcadas as identidades. Nesse ínterim, tem-se o entendimento de que este trabalho trata de dois grupos étnicos, os quais historicamente têm particularidades entre si, assim como o processo imigratório desses grupos teve algumas diferenças, como, por exemplo, a colonização dos alemães foi muito anterior a dos italianos. Entretanto, é possível realizar algumas análises em conjunto e de forma comparativa, em especifico aqui, observa-se o percurso escolar dos dois grupos.

Ao analisar as narrativas do banco de dados nota-se que nenhum dos descendentes de alemães estudou na Escola Garibaldi. Decerto que o critério da distância da localidade dos alunos até a escola não deve ser desconsiderado, porém nota-se que havia relações étnicas identitárias estabelecidas nesse contexto. Mesmo a Escola Garibaldi sendo pública, os alemães preferiam outras instituições escolares. Para melhor problematizar as fontes foi necessário observar aonde estudaram os descendentes alemães. Cinco, dos sete entrevistados, estudaram no colégio do professor Oscar Fischer. É importante registrar que nenhum dos italianos estudou com esse professor. Não há pesquisas mais consistentes sobre esse professor e essa escola, entretanto a partir da fala dos entrevistados fica perceptível que as aulas eram dadas em português e, também, em alemão e a escola era comunitária e particular. Fato que explica os italianos não estudarem com esse professor e também os alemães não estudarem na Escola Garibaldi, onde o ensino era em português, item que será aprofundado.

Um dos entrevistados da pesquisa, de origem alemã, não foi identificado aonde ele havia estudado, porém nota-se que após 1977 foi atuar como professor na Escola Garibaldi. Não se pode deixar de mencionar que nesse momento a Escola Garibaldi já tinha construído seus prédios novos e já não era mais uma escola multisseriada, assim adquiriu outra característica (CASTRO, 2017). O que se quer dizer aqui é que nesse momento, no ano de 1977, a Escola Garibaldi possuía mais professores e o pertencimento étnico não se fazia tão presente ${ }^{4}$.

Outro dado interessante a ser mencionado é um descendente de origem italiana que estudou em uma escola étnica alemã no município vizinho de Morro Redondo (RS $)^{5}$. Conforme a entrevistada ela era ensinada em português, enquanto os demais colegas em alemão, em suas palavras:

E: E daí passou os anos, lembrando né, saí muito com meus avós. Aí depois fui para casa, me lembro, meus pais em colocaram no colégio, veja bem que colégio, ai meu pai se mudou daí de Canguçu né, ele se mudou pra Morro Redondo, eu tinha dois anos, ele saiu da casa dos meus avós, casado né e eu tinha dois anos, eu e o Luís meu irmão mais velho, fomos morar no Morro Redondo. E na época eu meio parava na vó, na minha vó que era muito querida, a vó Pegoraro essa, Catarina. E depois os meus pais colocaram no colégio, sabe, colégio do lugar (?). Naquela época não tinha, lá no Morro Redondo era puro alemães, não tinha colégio público, era colégio de alemães, era o colégio que eu frequentei, então me ensinaram brasileiro e os outros alemães, e eu fui pegando o alemão, era fácil no meio dos outros (MECOM 32) ${ }^{6}$.

\footnotetext{
${ }^{4}$ Nesta década a Escola Garibaldi passa a ser uma escola seriada, ou seja, há a necessidade de contratação de mais professores.

${ }^{5}$ Aproximadamente $50 \mathrm{~km}$ de distância.

${ }^{6}$ Essas entrevistas que são acervos foram utilizadas da maneira que estavam transcritas, porém optou-se por referir pesquisador pela letra $\mathbf{P}$ e o entrevistado pela letra $\mathbf{E}$. Nas entrevistas do banco de imagens e sons do MECOM optou-se por não identificar os sujeitos entrevistados e sim nomeá-los com a sigla "MECOM" seguidos da numeração.
} 
Mais adiante na narrativa, a entrevistada menciona que também aprendia em alemão:

P: A senhora chegou a estudar?

E: Mas pouco, em alemão, dois ou três anos...

P: Estudava em alemão?

E: Estudava, mas ensinava em brasileiro, fazia contas em alemão (MECOM 32).

Neste momento, nota-se que mesmo os ítalo-brasileiros estudaram, por vezes, em escolas alemãs. Nessa narrativa em específico, percebe-se que havia o critério logístico presente. A entrevistada ao se mudar para Morro Redondo teve como opção estudar nessa escola alemã, assim sendo estudou tendo aulas em outro idioma.

Com isso, percebe-se que havia, sim, algumas especificidades. Porém, algumas recorrências e permanências são sentidas. Claro que esta pesquisa é localizada e restrita a essas narrativas, entretanto é possível chegar a algumas considerações, sem, portanto, pretender generalizações. Como já referido anteriormente, notou-se algumas regularidades no processo escolar dos descendentes de origem italiana e alemã. Uma delas é alguns dos italianos terem realizado seus estudos na Escola Garibaldi, a qual sempre foi pública. Nesse momento são oportunas as reflexões de Luchese (2007), para a autora as escolas públicas, laicas e gratuitas eram com frequência solicitadas pelos imigrantes ao governo.

Quanto aos italianos solicitarem escolas públicas, é pertinente pensar a Escola Garibaldi. Esta sempre esteve aliada ao poder público e permanece em funcionamento sem interrupção até os dias atuais. Porém, ela foi precedida por outras instituições, como uma escola comunitária a qual acabou fechando. Assim, pode-se problematizar a questão de que esse grupo étnico preferia as escolas públicas e solicitava-as. Diferentemente do que se percebe no processo imigratório dos imigrantes de origem alemã, para estes a escolarização estava aliada à religiosidade ${ }^{7}$.

Para Werle e Metzler (2010), o governo brasileiro, preocupado com o ensino ministrado em língua estrangeira, tomou algumas medidas ao longo dos séculos XIX e XX nas áreas de imigração, como, por exemplo, a abertura de escolas públicas. Neste momento, pode-se pensar que a criação da Escola Garibaldi em 1928 por parte do poder público serviria, também, como um meio de nacionalização ao grupo imigrante.

Quando ao percurso escolar dos descendentes de italianos, além dos que estudaram na Garibaldi, os demais entrevistados frequentaram colégios na cidade vizinha de Canguçu ${ }^{8}$, em casa com familiares, com irmãos mais velhos que estudaram na Garibaldi. É importante registrar que dos 18 narradores, não foi possível observar qual foi o percurso escolar dos entrevistados em cinco entrevistas.

Somente um aluno descendente de italiano estudou em um colégio particular, essa entrevistada residia na cidade vizinha de Canguçu. Conforme registrado antes, esse grupo étnico tinha por preferência as escolas públicas. Das narrativas dos ítalo-descendentes selecionaram-se alguns trechos para a problematização.

E: Esse aqui ó, esse tal de Egidio [mostra a foto], é parente desse aqui, Miguel Soares...

P: Professor também?

E: Esse aqui não tinha colégio na época, ele deu aula na Igrejinha que tinha na comunidade São José, que ele ia ser padroeiro. Esse foi nosso primeiro professor [...] (MECOM 1).

\footnotetext{
${ }^{7}$ Sobre esse assunto ver: Kreutz (1994, 1998, 2000); Dreher (1990).

${ }^{8}$ Aproximadamente $55 \mathrm{~km}$ de distância.
} 
E: É, tudo em português. O falecido monsenhor também deu aula para muitos alunos aí, ajudo muito a turma aí (MECOM 13).

Nesses dois trechos de entrevistas é possível perceber a relação existente entre Igreja e escola. Aulas eram realizadas no espaço da Igreja, assim como os líderes religiosos ministravam aulas para alunos. Em zonas de imigração italiana, a religiosidade, majoritariamente a católica, estava presente na vida comunitária (LUCHESE, 2007). Nas narrativas dos entrevistados, dos alunos da Escola Garibaldi, foi rememorada a presença do padre na escola ministrando as aulas de catequese, mesmo sendo uma instituição pública. Com isso, nota-se a presença religiosa neste ambiente escolar. Quanto aos descendentes de alemães, Weiduschadt (2007) observa em sua dissertação de mestrado que as escolas ligadas a instituições religiosas luteranas estiveram presentes entre os imigrantes alemães no Rio Grande do Sul.

Ainda nas narrativas dos descendentes italianos, observaram-se lembranças sobre a alfabetização em casa:

E: Teve uma época no colégio aí o professor me ensinava a ler soletrando, e o meu pai não podia ver aquilo, não aceitava. Então ele me tirou do colégio e disse que ele mesmo ia me ensinar. E ele me ensinou...

[Os dois falam juntos]

P: E aí aprendeu o italiano?

E: Aprendi [muito baixo]. Mas tudo o que eu sei aprendi com ele, mas quase todos os filhos ele alfabetizou, só eu me lembro o meu irmão, quer era mais velho do que eu, que foi no colégio (MECOM 10).

Ainda neste conjunto de entrevistas, é possível notar que o tempo da escola faz-se presente na memória dos depoentes:

P: Quando vocês eram pequenos a senhora lembra?

E: Sim, lembro de quando tinha 13 anos e ia para o colégio, parece que estou indo (MECOM 24, grifo nosso).

P: E da sua infância, assim, o que que o senhor lembra mais? O que que marcou assim, da sua infância?

E: Sei lá, colégio... (MECOM 25).

Quanto ao grupo dos alemães (sete narrativas), cinco dos entrevistados estudaram no colégio do professor Oscar Fischer, onde conforme essas narrativas o ensino era dado em português e em alemão. Nas outras duas entrevistas não foram identificadas onde haviam estudado. Um desses entrevistados, de origem alemã, foi ministrar aulas na Escola Garibaldi posteriormente, ele relembra que sua esposa que era de origem italiana não falava o italiano, e ele, por sua vez, sabia o alemão, apenas não utilizava muito.

Conforme um dos entrevistados, os alemães importavam-se em preservar mais o idioma do que os italianos:

P: Agora a gente já não fala mais?

E: Não, alguma coisa a gente entende, deixaram, foram criando, e se criando... O italiano é diferente do alemão, já é mais tradicionalista, o italiano não, abandonou, o alemão não, o alemão fala sempre em alemão, pode pegar qualquer guri que fala em alemão, e os italianos aí não falam... (MECOM 2). 
Voltando ao colégio do professor Oscar Fischer, esse era um colégio pago. Conforme as memórias:

P: O senhor estudou aonde?

E: Eu estudei na São Manoel, no colégio do Oscar Fisher.

P: Do Oscar Fisher.

E: Era colégio de comunidade, não era assim, vamos dizer como do município, compreende? Era particular o pai pagava uma mensalidade, pagava, me lembro bem, 3 mil réis por mês tinha direito. O próprio professor era reverendo também então, nós participávamos da igreja e mais o colégio.

P: O ensino era em português?

E: Eram as duas, era português e tinha um dia por semana que se estudava o alemão.

P: Ai o senhor aprendeu alemão?

E: Na época aprendi, depois esqueci de novo.

P: Era alemão mesmo ou era pomerano?

E: Não, alemão.

P: E a formação religiosa do senhor?

E: Era luterana (MECOM 6).

P: E naquela época a senhora estudou aqui na colônia mesmo?

E: É, ali no colégio Fischer.

P: Colégio Fischer?

E: É pertinho aí $[\ldots]$

P: e a aula era em português?

P: E a aula era em português, não em alemão?

E: Era misturado.

P: Ah, misturado.

E: Aham.

P: O professor era da onde?

E: Professor era o Oscar Fischer. Agora ele já é falecido (MECOM 9).

Os entrevistados rememoram que esse era um colégio da comunidade, particular, sendo necessário o pagamento de mensalidade. Os imigrantes de origem alemã tinham interesse na manutenção do seu idioma, logo as escolas públicas, com o ensino em português, não eram sempre as mais requisitadas, como é o caso dos italianos. Nesses excertos das narrativas nota-se também a relação entre escolarização e religiosidade, aspecto comum nesse grupo étnico. A narrativa relembra que o professor Oscar Fischer era também reverendo, assim os alunos participavam da vida escolar e religiosa local. Para os descendentes de imigrantes alemães a escolarização estava aliada a religiosidade, o grupo estruturava-se em torno desses pilares ${ }^{9}$. Por isso, também, era importante para esse grupo a manutenção do idioma alemão e a preferência por escolas que ministrassem, ainda que não integralmente, o ensino em alemão. Pela data de nascimento desses entrevistados, de origem alemã, nota-se que alguns deles possivelmente estudaram no período da Nacionalização do Ensino. Uma das pessoas entrevistadas rememora que em um salão de baile foi necessário o hasteamento da bandeira para mostrar que eram brasileiros. A mesma entrevistada relembra que na escola foi sentida a nacionalização. Conforme a narrativa, o alemão foi utilizado na escola, mas depois foi proibido:

\footnotetext{
${ }^{9}$ Ver nota de rodapé 9.
} 


\author{
P: Por que ele hasteou a bandeira brasileira? \\ E: para dizer que ele era brasileiro. \\ P: Na escola então falavam? \\ [...] \\ E: Na escola um dia por semana nós estudávamos o alemão. Depois \\ sim, eles proibiram, mas no início não, no início nós estudávamos. \\ Depois foi proibido (MECOM 6).
}

Para Weiduschadt (2009), os imigrantes de origem alemã possuíam uma organização escolar para seus filhos, tinhas suas escolas comunitárias étnicas e confessionais e nestas privilegiavam a língua alemã. Havendo, dessa forma pressão nessas localidades para cultivar a nacionalidade brasileira. Entretanto, conforme a autora, se por um lado, havia a imposição à nacionalização, por outro, não havia ainda antes da década de 1930 a fiscalização em todas as escolas. Na década de 30, o governo de Getúlio Vargas criou as condições e mecanismos favoráveis para efetivar a nacionalização.

Conforme Corsetti et al (2007), as políticas para a nacionalização do ensino tiveram impacto, sobretudo, nas regiões de colonização italiana e alemã. Sentiram os efeitos dessa lei as escolas étnicas, confessionais, comunitárias ligadas a grupos étnicos, os quais tinham interesse na manutenção de seus costumes e de sua língua ou dialeto.

Dois dos entrevistados de origem alemã foram professores e evocam suas lembranças no momento da construção das entrevistas, assim neste ponto doe texto serão analisadas essas memórias.

P: Aonde é que a senhora lecionou?

E: Lecionei em muitas escolas. Comecei na "Oliveira" que é a Escola Ipiranga. Fica perto de Canguçu. Depois invertendo. Eu fiquei doente, essa perna sempre me incomodando [...[época não tinha, como agora, que tem tudo né? Que tem conforto para ir ao colégio, tudo [...]. Depois então, a escola Princesa Isabel, que fica aqui na colônia São Manoel. Escola de comunidade. Depois foi a escola Júlio de Castilhos, outra escola de comunidade. Fica pertinho. Depois, tem a Santa Helena, aqui no (?) também, escola de comunidade. Uma luterana, outra episcopal, depois eu (?) do Alegrete onde me aposentei [...]

P: Sim.

E: Ali que eu lecionei. Trabalhei muitos anos.

P: E essas escolas da comunidade, não, não pertenciam a prefeitura?

E: Pertenciam. Era... pertenciam...

P: E era do governo?

E: Era do governo. As escolas era do governo. Era do governo que... O terreno era da comunidade, a escola era do... Então às vezes eles davam a casa né, da comunidade, pra ter escola, né?

P: Da prefeitura?

E: É, da prefeitura. Mas depois, eles faziam o prédio, né... Era convênio. Entre o município e a comunidade (MECOM 30).

A partir dessa evocação nota-se que a entrevistada foi professora em muitas escolas, a maioria delas, escolas comunitárias. A rotatividade dos professores em escolas, sobretudo nas rurais, era algo recorrente. Castro (2017) observa, em sua dissertação de mestrado, que a permanência de professores em escolas rurais está alinhada ao envolvimento comunitário do docente, ademais em espaços de imigração havia aspectos étnicos identitários envolvidos. 
A entrevistada relembra sobre sua família, ressaltando que muitos foram alfabetizados em casa pelos próprios familiares, demonstrando a importância atribuída à aprendizagem.

Mesmo este artigo pautando-se especificamente no processo escolar dos descendentes de origem italiana e alemã, foi perceptível que está presente a relação desses grupos com a religiosidade e com o trabalho, sendo que não são elementos distanciados da escolaridade. Assim, será dada atenção a essas duas categorias.

\section{Religiosidade e trabalho no contexto da imigração na Serra dos Tapes}

Nas entrevistas analisadas há muitas recorrências em relação à religiosidade e a valorização do trabalho. De forma geral, os imigrantes atribuem importância ao trabalho, são valores considerados importantes para o grupo, tanto para os de origem alemã como italiana. Em suas memórias ao emigrarem para o Brasil e iniciarem suas vidas nos lotes coloniais foi preciso muito trabalho para vencer as adversidades na nova pátria, isso está presente na memória coletiva, sendo repassado para as gerações seguintes. É válido fazer referência que as pessoas entrevistadas não foram as que vieram para o Brasil, mas, sim, os descendentes, os quais rememoram, muitas vezes, a partir do que ouviram de seus antepassados. São as memórias dos outros ou na perspectiva de Pollack (1992), os acontecimentos vividos por tabela. Em relação a religiosidade dos italianos, pode-se apoiar em Luchese (2007, p. 91), conforme a autora estes indivíduos que imigraram eram, em sua grande parte, católicos e "trouxeram da Itália uma religiosidade com práticas e valores diferenciados daqueles aqui vivenciados". Desta forma, uniam-se em um esforço comunitário para construir capelas nas colônias. Próximo à capela da colônia, eram criadas outras instituições de igual relevância para os imigrantes, tais como cemitério, escola, salão de festas para a comunidade (LUCHESE, 2007). Para os alemães a religiosidade, igualmente, era um dos elementos essenciais, Weiduschadt (2007) observa que havia a preocupação com a consolidação da língua alemã, além disso igreja e escola estavam relacionadas como uma forma de propiciar valores morais e religiosos ${ }^{10}$.

Desta forma, ao analisar a trajetória escolar desses imigrantes não se pode deixar de considerar esses elementos, pois muitas vezes a escola estava aliada a Igreja. Outro ponto interessante a ser explicitado é a relação entre as duas etnias, alemã e italiana, e entre a religião dos dois grupos, uma das entrevistas:

P: Tinha um padre desde o começo?

E: Eu acho que deveria ter, porque eu lembro que o falecido meu avô falava que tinha um padre que parava na casa dele quando vinha rezar a missa. O padre dormia lá. Às vezes, se juntavam todos os italianos da roça e iam para lá conversar à noite.

P: E eram todos católicos?

E: Sim, todos esses de origem italiana eram católicos.

P: Os alemães seguiam a religião protestante ${ }^{11}$ ?

E: Sim, os alemães tinham a religião deles (MECOM 7).

\footnotetext{
${ }^{10}$ Conforme Weiduschadt (2007) no contexto da região Sul do Rio Grande do Sul, entre os imigrantes alemães houve três tipos de luteranismos, a primeira opção dos imigrantes alemães em meados do século XIX foi pelas Igrejas independentes, ou seja, não filiada a nenhuma ordem religiosa, escolhiam entre os membros da comunidade aquele considerado com melhor capacidade para ser o pastor. Posteriormente se instalou igrejas institucionais luteranas: o Sínodo Riograndense, ligado a Alemanha e o Sínodo de Missouri, de procedência norte americana.

${ }^{11}$ Ao falar em protestante eles se referem ao luteranismo, podiam ser dos três tipos como referendado na nota de rodapé número 11 .
} 
Nessa narrativa é explicado a religiosidade dos grupos, os italianos ligados à Igreja católica, e os alemães, nessa região, eram protestantes. Ainda, é rememorado sobre um padre que ficava na casa das pessoas da comunidade, denotando a relação entre a comunidade e a religiosidade, era atribuída importância aos aspectos espirituais do grupo. Outra narrativa aborda sobre a relação entre as etnias e os casamentos:

P: E sobre casamentos...

E: Ah primeiro tinha eu passar pelos pais.

E: É, e casar religião católica, tinha que ser né, a evangélica ${ }^{12}$ não. Mas depois com o tempo foi melhorando, até se a noiva quisesse casar, então tinha que se batizar de novo, o padre não tolerava (MECOM 5).

Outra entrevista reforça na mesma linha de pensamento:

E: Si, si, os alemães gostavam dos italianos.

P: Faziam festa juntos?

E: Fazia festa junto. A vez muito casamento, mas os italianos nunca queriam deixar os filhos casar com alemão.

P: Ah, é.

E: Eu casei, namorei um alemão, mas eu, Deus que me perdoe, depois tinha que virar de religion. Os italianos eram só de católicos e os alemães são de outra religião. Mas que meu pai ia deixar, não mesmo! (MECOM 10).

Essas memórias referem-se há um período de tempo mais distante do presente e mais próximo do período da colonização, onde havia demarcação étnica estabelecida. Outra entrevistada rememora acerca de um período de tempo mais recente, em suas palavras:

E: Tinha um padre que veio aqui e não era católico. Era companheiro do nosso padre tudo, agora acabou, os padres são tudo unido. Os alemães, os católicos e os protestante, tudo unido. Quando tem festa na igreja de alemão os católicos vão, e quando tem a festa dos italianos, os padres, como é aquele... evangélico. Por quê tem a evangélica, tem a luterana, tem a protestante ${ }^{13}$. Acho que mais dos católico e protestante (MECOM 10).

É possível perceber a união das Igrejas para em um esforço comunitário realizar empreendimentos e conseguir as instituições de que necessitavam:

E: Não. Se conseguiu colégios, aquele colégio foi feito pelas comunidades também, luteranas, episcopal e católicas, a mão- deobra toda, veio dinheiro mas a mão-de-obra foi das comunidades. Se conseguiu posto de saúde, claro a obra não foi da comunidade, foi uma conquista. $\mathrm{O}$ posto policial, só que agora está sem brigada, foi uma conquista das comunidades também, com uma campanha de doação do material, eu mesmo doei mil tijolos, donativos e mão- de-

\footnotetext{
${ }^{12}$ Nesse contexto ao falar em evangélicos, os entrevistados estão se referindo aos luteranos.

${ }^{13}$ Havia a diferenciação por parte dos entrevistados, entretanto todas são luteranas e podem variar dos três tipos.
} 
obra. E, a gente é muito amigo. Todos os anos tem a semana da unidade, tem o culto ecumênico na católica, depois tem o culto ecumênico na luterana, depois tem o culto ecumênico na episcopal, e a gente vai um na comunidade do outro (MECOM 19).

Como mencionado anteriormente, a religiosidade e a escolarização são elementos associados nessa conjuntura dos imigrantes. Como já foi referido, outra categoria presente, de forma intensa nas memórias, refere-se ao modo como esses grupos lidavam com o trabalho. $\mathrm{O}$ que se percebe, nestes momentos, é o discurso acerca das dificuldades e a força de trabalho do colono imigrante para vencer esse começo de vida. É visível, em muitas delas, a "exaltação" aos antepassados que imigraram para o Brasil e as dificuldades enfrentadas.

É oportuno mencionar que há o entendimento que ao chegar nos lotes coloniais, os imigrantes passaram por inúmeras dificuldades. O que está se problematizando aqui é a memória consolidada nas gerações seguintes.

$\mathrm{Na}$ fala percebem-se alguns discursos sobre o imigrante e seu espírito desbravador que, ao chegar ao Brasil, trabalhou muito para conseguir o que necessitavam, incluindo as construções das escolas. Pode-se perceber, na fala dos entrevistados, a lembrança dos antepassados ancorada no imaginário, há inúmeros discursos do desbravamento e da resistência comunitária nos primeiros tempos de instalação nos núcleos coloniais.

É permissível refletir sobre a memória coletiva. A memória coletiva (HALBWACHS 2003), está atrelada a um grupo e quanto menor esse grupo maior a possibilidade de uma memória grupal (CANDAU, 2014). Observa-se essa categoria nas narrativas referentes a vinda dos imigrantes para a região e o início da vida na localidade. São recorrentes as rememorações sobre o que passaram seus antepassados ao iniciar a colonização, é uma memória consolidada nas pessoas da localidade, configura-se como uma memória coletiva daquele grupo. Assim, selecionou-se alguns trechos das entrevistas que convergem nesta direção:

E: Mas vou conta um pouquinho da história da vida que nós começamos [...] Quando nós viemos pra cá, vinha um filho no colo, e outro na barriga, fazia dois anos de casado. A casa eu vim trabalhar de terra, dava trinta por cento do que produzia para o patrão [...].

E: Ih vieram aí no meio do mato né. Moravam assim, faziam... A primeira casa que eles fizeram era tábua, de tábua assim, bruta. Mas ai eu não sei dizer se era eles que serravam, como era, devia ser com serrote aquela época [...] (MECOM 1).

P: Como é que era a vida na sua infância?

E: A vida foi boa, nunca falto nada...

P: O que é que faziam?

E: Ah trabalhava, desde guri pequeno sempre trabalhei na lavoura.

[...] Mas nós ia no colégio de manhã e de tarde nós ia pra lavoura, não é como hoje, hoje se queixam, hoje o ônibus vem na porta da casa te buscar, buscar o aluno pra levar pro colégio, aquela época fazia acho que cinco ou três quilômetro de a pé, pra ir no colégio. O ruim hoje é que tu não pode ensinar uma criança, não é vontade de trabalhar [...] (MECOM 2).

E: Naquele tempo, a gente trabalhava muito [...] Hoje a vida é fácil, temos máquina para tudo. Não tem mais boi que lavra, tem muitos que quase nem trabalham. Se trabalhassem como quando nós nos criamos [...] (MECOM 7). 
E: Na infância, nós todos trabalhávamos na lavoura. Me lembro que, quando nós éramos pequenos, o papai agarrava a enxada, botava um cabinho pequeno e nos levava para nos ensinar a capinar feijão e milho (MECOM 12).

E: A senhora tem recordações do que faziam na infância, na época aqui na vila?

E: Sim, naquela época trabalhávamos na lavoura, desde quando casei, lavrando, carroceando, todos os serviços que fazem na lavoura (MECOM 27).

E: Ali chama-se Ares Alegre, $1^{\circ}$ distrito de Canguçu. É tão fácil de ir ali, ontem mesmo eu passei lá. Ainda andei falando com primo, que ele está doente, gostaria de dar um chego lá, tão fazendo uma estufa de fumo, para ver como os italianos não eram preguiçosos né, (MECOM 32, grifo nosso)

Nesses trechos das narrativas são permissíveis algumas considerações, as evocações estão carregadas da representação que o trabalho lhes confere determinada identidade, ou seja, a construção identitária dos que se consideram "italianos" está alicerçada no ethos da laboriosidade, no comprometimento da manutenção da propriedade e, consequentemente, da manutenção da comunidade.

Rememorações relacionadas ao começo na vida na colônia e o vencimento das dificuldades foram atribuídas muito a capacidade de trabalho dos colonos. Os imigrantes atribuíam valor ao seu trabalho de desbravar e colonizar o espaço a eles destinado. E dessa forma, por passarem muitas dificuldades nos primeiros tempos, consideravam que seu trabalho era digno e os descendentes compartilhavam dessa memória. Nesse ponto é possível pensar na identidade desse grupo, uma vez que a identidade é relacional, ou seja, demarcada na diferença (HALL, 2014). A afirmação da identidade de que os imigrantes eram pessoas que trabalhavam muito é demarcada em comparação com outros grupos, assim pode-se colocar alguns questionamentos, como, por exemplo, com quem se compara? Com o negro escravo? Com o latifundiário? Com o campeiro? Com os "brasileiros? ${ }^{14 "}$ Woodward (2014) explica sobre identidade e diferença, conforme a autora ao dizer o que somos, também se diz o que não somos (WOODWARD, 2014). Assim, os grupos de imigrantes ao autodenominarem-se como pessoas que valorizavam o trabalho, o faziam em comparação com outros grupos, ou seja, relacionando a sua identidade com a do outro.

Outro item refere-se às narrativas acerca de que o tempo passado era melhor, de que hoje em dia é diferente a relação das pessoas com o trabalho, sobretudo o rural. Um dos entrevistados recorda que o tempo do trabalho era aliado ao tempo da escola, estudava-se em um turno e trabalhava-se no outro, na maior parte das vezes na lavoura. Ainda, no último excerto, selecionado para este texto, nota-se a etnicidade presente, ao falar sobre o trabalho, a entrevistada diz que "era trabalho para mostrar como os italianos não eram preguiçosos". Percebe-se aqui elementos étnicos presentes, a relação entre o grupo dos italianos e o trabalho. Aqui se pode também fazer uso da mesma teorização da invenção das tradições proposto por Hobsbawm e Ranger (2012), pois esses depoentes consideram-se, em alguns casos, como italianos. Em algumas falas dessas entrevistas, encontra-se um discurso referente aos "brasileiros e nós". Os entrevistados não nasceram no Brasil, são descendentes da $3^{\mathrm{a}}$ ou $4^{\mathrm{a}}$ geração dos imigrantes que vierem e, mesmo assim, há a construção desse sentimento de italianidade ${ }^{15}$.

\footnotetext{
${ }^{14}$ Alguns entrevistados se denominam de "italianos" ou "alemães", e se referem aos outros como "os brasileiros".

15 Para Iotti (2001, p. 53), "o sentimento de italianidade surgiu no Brasil e, também, foi incentivado pelo Estado italiano, preocupado em interligar emigração, comércio e manutenção da identidade cultural [...]”.
} 
No que se refere ao conjunto de entrevistados dos descendentes de alemães, esse item do trabalho também foi recorrente. Esse grupo atribui valor ao seu trabalho, as dificuldades iniciais de colonizar o espaço foram superadas com a força de trabalho dos que vieram para o Brasil. Ainda, observam-se trechos de entrevistas onde os narradores destacam a boa relação entre os italianos e os alemães, uma vez que ambos tinham as mesmas concepções de trabalho. Alguns excertos das narrativas vão ao encontro dessas afirmações: "P: [...] nunca deu problema. Nossa relação quando trabalhávamos juntos nunca deu problema" (MECOM 6). O mesmo entrevistado, de origem alemã, relembra que aprendeu a fazer vinho com um conhecido de origem italiana: P: Com quem o senhor aprendeu a fazer vinho? E: Foi o Casarin que me ensinou o filho da dona das terras, Pedrinho, era Pedrinho também (MECOM 6). Nesse momento, é permissível pensar na questão identitária desses grupos e no espaço que os entrevistados vivem. Há uma proximidade geográfico dos descendentes das duas etnias. Outrossim, por se considerarem pessoas que valorizavam o trabalho, os dois grupos não tinham problemas nesse sentido. Ainda, é possível estabelecer conexões quanto a religiosidade, os entrevistados rememoram que cada um tinha a sua religião e frequentavam igrejas diferentes, mas a religiosidade estava presente tanto nos imigrantes italianos quanto nos imigrantes alemães.

Seguindo na argumentação sobre o trabalho dos alemães, selecionou-se um trecho das narrativas, para o entrevistado:

\section{P: De que era a fábrica?}

E: Era de pêssego, de compota, nós trabalhamos quinze anos. Era pepino, de tudo. Nós tínhamos lá pessegada, de tudo a gente vendia.

$\mathbf{E}: \mathrm{Ah}$ ! A senhora lembra até que época funcionou?

E: Olha, mas nós, nós trabalhamos quinze anos nessa fábrica

E: Olha, não sei lembrar. Já faz tanto tempo... Aí a gente construiu aquela fábrica, que trabalheira deu né? Depois a gente fez essa casa aqui (MECOM 9)

E: Aqui, ali naquela granjinha, que tem ali em baixo, aquele prédio grande que tem ali. Ali que nos criamos, moremos anos ali. Tem uma criaçãozinha de animal, vaca de leite né, porcos, bastante. E um (?) nos demos farelo para os porcos, vacas, cavalos (?). Naquele tempo não existia esse negócio de maquinário, tudo aqui. Era tudo feito a braço (MECOM 18).

A partir das narrativas, percebe-se a importância concedida ao trabalho também pelos descendentes de alemães.

\section{Algumas considerações}

O objetivo deste artigo foi analisar um conjunto de entrevistas, as quais são acervos, e realizar algumas comparações entre as memórias dos descendentes italianos e alemães. Em uma primeira investigação observou-se que a maioria dos entrevistados eram ítalodescendentes, das 30 narrativas, 18 eram de descendentes de italianos, e apenas 7 de alemães. Esses números são facilmente explicados se for levado em consideração que as entrevistas foram realizadas, sobretudo, na região de colonização italiana e tiveram como objetivo preservar a memória dos imigrantes daquela região. Porém, ainda que haja uma maior quantidade de memórias deste grupo étnico, foi possível estabelecer conexões entre as narrativas dos dois grupos. Percebeu-se que há algumas semelhanças quando se estuda a 
escolarização e a educação em áreas de imigração. Por outro lado, identificou-se também algumas particularidades de cada etnia.

Nas convergências pode-se perceber a importância concedida a educação e a escolarização pelos dois grupos. Independentemente do tipo de escola ou se foram alfabetizados em casa, essas memórias estão carregadas do quanto era necessário nessas comunidades as iniciativas escolares. Da mesma forma, foi possível notar que a religiosidade se faz presente neste contexto, além disso está aliada a escolarização; aulas eram dadas no espaço da Igreja, assim como os líderes religiosos participavam do espaço escolar. Mais uma característica destes grupos étnicos é a relação com a religiosidade, ao imigrarem da Europa para o Brasil esses grupos trouxeram consigo valores vivenciados na terra natal, e isso foi repassado entre as gerações. É necessário assinalar que os italianos eram católicos, enquanto que os alemães, emigrados para essa região, eram, na maioria dos casos, luteranos, entretanto o que se conseguiu observar foi a presença da religiosidade nesses grupos e a relação com o universo escolar. Alguns entrevistados também ressaltam que atualmente ${ }^{16}$ há a união entre as Igrejas da região, unindo-se em prol das demandas que surge nas comunidades.

Como já mencionado, no que tange ao processo escolar dos ítalo-brasileiros e dos teuto-brasileiros, a partir das narrativas analisadas, foi possível perceber algumas especificidades de cada um dos grupos. Nas memórias evocadas pelos italianos, muitos desses estudaram na Escola Garibaldi, escola pública da região, situada em colônia de italianos. No que se refere aos alemães, nenhum deles estudou na Escola Garibaldi. Esses em sua maioria, foram alunos no colégio do professor Oscar Fischer, o qual ministrava parte das aulas em alemão. Os descendentes de italianos, nenhum deles, estudou nesse colégio. Uma das inferências pertinentes diz respeito a língua alemã; os alemães tinham interesse na manutenção de seu idioma, logo preferiam as escolas que tinham o ensino em alemão, ainda que somente alguns dias, e por isso não estudavam na Garibaldi. Por outro lado, os italianos, talvez, não tivessem o interesse em se alfabetizar na língua alemã, por isso não estudavam no colégio do professor Oscar Fischer, além do que essa era uma escola particular, era necessário o pagamento de uma mensalidade por parte dos pais dos alunos, e conforme referenciado por Luchese (2007), os italianos tinham por preferência as escolas públicas.

Ainda, o texto discorreu sobre a valorização do trabalho por parte dos imigrantes, estabelecendo conexões com a identidade relacional, ou seja, os colonos consideravam seu trabalho digno por desbravaram os lotes coloniais e isso é repassado aos seus descendentes que rememoram essas memórias como suas. Tanto nas memórias dos descendentes alemães quanto dos italianos são evocadas lembranças do quanto a vida no início da colonização foi difícil, e as dificuldades foram superadas com o trabalho. Da mesma forma, os entrevistados consideram que as duas etnias tinham boas relações na localidade, pois partilhavam das mesmas noções em relação ao trabalho e também a religiosidade.

As discussões estiveram tangenciadas por reflexões sobre a identidade étnica e grupo étnico. Dessa forma, ao pensar na trajetória escolar dos descendentes de imigrantes italianos e alemães, é necessário o esclarecimento de que as rememorações estão imbuídas do sentimento de pertencimento. Porém, as fronteiras não são fixas e imutáveis, em algumas narrativas podese notar que os dois grupos conviviam de forma harmônica no mesmo espaço territorial ou de sociabilidade, mas percebem-se, também, algumas falas no sentido de hábitos próprios de cada um dos grupos. Nota-se também a junção dos grupos e das lideranças religiosas, de três orientações, na década de 1970 para a construção dos novos prédios da Escola Garibaldi, o que é demonstrativo da importância que esses grupos concediam a escolarização e organizavam-se para isso. É importante registrar aqui que as escolas étnicas comunitárias foram fechadas com a nacionalização compulsória do ensino a partir de 1938, dessa forma, é

\footnotetext{
${ }^{16}$ Necessário lembrar que as entrevistas foram realizadas entre os anos de 2000 e 2006.
} 
possível que as memórias dos entrevistados sobre o colégio do professor Oscar Fischer referem-se a um período de tempo anterior a esse, ou pelo menos reprimiu-se o uso da língua alemã nesse colégio, sendo o ensino ministrado em português. Os conceitos de identidade e identidade étnica foram aqui utilizados na sua visão não-essencialista, ou seja, com o entendimento de que a identidade é construída, decerto que o meio geográfico influencia, entretanto mais do que isso, as relações sociais estabelecidas e o compartilhamento de códigos culturais é o que dá consciência a um grupo étnico. Aliado a isso, as lembranças da terra natal de seus antepassados são perpassadas de uma geração para outra, porém nesse processo há mudanças, adaptações, ou como diz Hobsbawn e Ranger (2012) há invenção das tradições.

Para finalizar é necessário mencionar que com esta pesquisa, apesar de ser localizada em uma região do Estado do RS, é possível compreender como os grupos étnicos enxergavam a escolarização, assim como elencar similaridades e diferenças entre os italianos e os alemães. Outrossim, é oportuno registrar a relevância da constituição de narrativas orais e da salvaguarda desses acervos, os quais potencializam a realização de diferentes pesquisas por diferentes áreas de conhecimento e ângulos.

\section{Referências}

AMADO, Janaína (orgs.). Usos e abusos da História Oral. 8.ed. Rio de Janeiro: FGV Editora, 2006.

AMADO, Janaína. O Grande mentiroso: tradição, veracidade e imaginação em história oral. In: História, São Paulo, p.125-136, 1995.

ANDERSON, Benedict. Comunidades Imaginadas. 4. reimpressão. São Paulo: companhia das letras, 2008.

BARROS, José D'Assunção. O projeto de pesquisa em história: da escolha do tema ao quadro teórico. Petrópolis: Editora Vozes, 2011. https://doi.org/10.18817/ot.v10i16.270

CASTRO, Renata Brião de. A Escola Garibaldi e o professor José Rodeghiero na Colônia Maciel - Pelotas (RS) (1928 - 1950): grupo local e etnia. 2017. 220 f. Dissertação (Mestrado em Educação) - Programa de Pós-Graduação em Educação, Universidade Federal de Pelotas. https://doi.org/10.21475/ajcs.18.12.06.pne1087

CERQUEIRA, Fábio Vergara et al. Museu Etnográfico da Colônia Maciel: a trajetória de um equipamento cultural dedicado à memória da comunidade ítalodescendente de Pelotas. Revista Memória em Rede, Pelotas, v.1, $\mathrm{n}^{\circ}$ 1, p. 70 - 85, 2009. Disponível em: <https://periodicos.ufpel.edu.br/ojs2/index.php/Memoria/article/view/9567>. Acesso em: 11 jun. 2015. https://doi.org/10.15210/rmr.v7i13.6304

CERTEAU, Michel de. A escrita da história. Rio de Janeiro: Forense Universitária, 1982.

CORSETTI et al. A política educacional no Rio Grande do Sul e a questão da Nacionalização do Ensino (1930/1945). História da Educação, n. 23, p. 173-192, 2007. Disponível em: < http://seer.ufrgs.br/asphe/article/view/29277>. Acesso em: 09 abr. 2015. https://doi.org/10.22456/2178-8839.54734

DREHER; Martin (org.). Populações Rio-Grandenses e Modelos de Igreja. Porto Alegre e São Leopoldo: EST/Sinodal, 1990. 
FERREIRA, Marieta de Moraes; Amado Janaína. Apresentação. In: FERREIRA, Marieta de Moraes; AMADO, Janaína (orgs.) Usos e abusos da História Oral. 8.ed. Rio de Janeiro: FGV Editora, 2006. https://doi.org/10.22409/economica.9i1.p137

GRAZZIOTIN, Luciane Sgarbi Santos; ALMEIDA, Dóris Bittencourt. Romagem do tempo e recantos da memória: reflexões metodológicas sobre História Oral. São Leopoldo: Oikos, 2012.

HALL, Stuart. Quem precisa de identidade? In: SILVA, Tomás Tadeu da (org.). Identidade e diferença: a perspectiva dos estudos culturais. Petrópolis: Vozes, 2014, p. 103-133.

HOBSBAWM, Eric. RANGER, Terence. A invenção das tradições. $2^{\mathrm{a}}$ ed. São Paulo: Paz e Terra, 2012.

KREUTZ, Lúcio. A educação de Imigrantes no Brasil. In: LOPES, Elaine Marta Teixeira; FARIA, Luciano Filho Mendes de; VEIGA, Cintia Greiva (orgs.). 500 anos de História da Educação no Brasil. $2^{\mathrm{a}}$ ed. Belo Horizonte: Autêntica, 2000. p. 347-370. https://doi.org/10.1590/s1413-24782000000200010

KREUTZ, Lúcio. Escolas de imigração alemã no Rio Grande do Sul: perspectiva histórica. In: MAUCH, Cláudia e VASCONCELLOS, Naira (orgs.). Os Alemães no sul do Brasil: cultura, etnicidade e cultura. Canoas, ULBRA, 1994. https://doi.org/10.18316/recc.v23i1.3925

KREUTZ, Lúcio. Etnia e educação: perspectivas para uma análise histórica. In: SOUSA, Cynthia Pereira de; CATANI, Denice Barbara (orgs.). Práticas Educativas, Culturais Escolares, Profissão Docente. São Paulo: Escrituras Editora e Distribuidora de Livros, 1998, p. 93-110.

KUHKMANN, Moysés Júnior; FERNANDES, Fabiani Silva. Periódicos e a História da Educação: base de dados como recurso metodológico. São Paulo: FCC/SEP, 2014.

IOTTI, Luiza Horn. $O$ olhar do poder: a imigração italiana no Rio Grande do Sul, de 1875 a 1914, através dos relatórios consulares. 2. ed. Caxias do Sul: EDUCS, 2001. https://doi.org/10.6026/97320630010381

LUCHESE, Terciane Ângela. Modos de fazer história da Educação: pensando a operação historiográfica em temas regionais. Revista História da Educação, Porto Alegre, v. 18, n. 43, p. 145 - 161, 2014. Disponível em: 〈www.scielo.br/pdf/heduc/v18n43/09.pdf> acesso em: 24 abr. 2015. https://doi.org/10.1590/s2236-34592014000200009

LUCHESE, Terciane Ângela. O processo escolar entre imigrantes na região colonial italiana do Rio Grande do Sul, 1875 a 1930: leggere, scrivere e calcolare per essere alcuno nella vita. 2007. 495f. Tese (Doutorado em Educação) - Programa de Pós-Graduação em Educação, Universidade do Vale do Rio dos Sinos, São Leopoldo, 2007. https://doi.org/10.21115/jbes.v8.n2.p108-117

PEIXOTO, Luciana Silva et al. Museu e identidade: o projeto da Colônia Maciel. Horizontes de maíz y barro: Foro Latino americano" Memoria e Identidad", Montevideo, p. 148, 2008. Disponível em www.fundacaobunge.org.br/uploads/.../museu_da_maciel_montevideu. acesso em 23 de março de 2015. https://doi.org/10.11606/t.16.2013.tde-27012014-110902 
PORTELLI, Alessandro. História oral e poder. Mnemosine, v. 6, n. 2, 2010. Disponível em: <www.mnemosine.com.br/ojs/index.php/mnemosine/article/.../pdf_183> acesso em: 25 mar. 2015. https://doi.org/10.21491/2237-3217/mnemosine.v6n1p203-217

POUTIGNAT, Philippe; STREIFF-FENART, Jocelyne. Teorias da etnicidade. 2. ed. São Paulo: Unesp, 2011.

VOLDMAN, Daniéle. Definições e usos. In: FERREIRA, Marieta de Moraes; AMADO, Janaína (orgs.). Usos e abusos da História Oral. 8.ed. Rio de Janeiro: FGV Editora, 2006. p. 33 - 41. https://doi.org/10.22409/economica.9i1.p137

WEIDUSCHADT, Patrícia. A nacionalização do ensino no contexto imigratório. ENCONTRO DA ASSOCIAÇÃO SUL RIO GRANDENSE DE PESQUISADORES EM HISTÓRIA DA EDUCAÇÃO, 15., 2009, Caxias do Sul. Anais... Caxias do Sul: ASPHE, 2009. https://doi.org/10.6026/97320630010381

WEIDUSCHADT, Patrícia. O Sínodo de Missouri e a educação pomerana em Pelotas e São Lourenço do Sul nas primeiras décadas do século XX: identidade e cultura escolar. 2007. 256 f. Dissertação (Mestrado em Educação) - Programa de Pós-Graduação em Educação, Universidade Federal de Pelotas, Pelotas, 2007. https://doi.org/10.21475/ajcs.17.11.03.pne219

WEIDUSCHADT, Patrícia; FISCHER, Beatriz T. Daudt. História oral e memória: aportes teórico-metodológicos na investigação de trajetórias docentes. In: FERREIRA, Marcia. Ondina Vieira.; FISCHER, Beatriz. T. Daudt; PERES, Lúcia. Maria Vaz. (orgs). Memórias docentes: abordagens teórico-metodológicas e experiências de investigação. São Leopoldo: Oikós, 2009.

WERLE, Flávia Obino Correa; METZLER, Ana Maria Carvalho. Contextos, institucionalização e práticas pedagógicas. In: WERLE, Flávia Obino Correa (org). Educação Rural: práticas civilizatórias e institucionalização da formação de professores. São Leopoldo, Oikós, 2010. p. 15-52. https://doi.org/10.14393/che-v15n3-2016-9

WOODWARD, Kathryn. Identidade e Diferença: uma introdução teórica e conceitual. In: SILVA, Tomás T. da (org.) Identidade e diferença: a perspectiva dos estudos culturais. Petrópolis: Vozes, 2014, p. 7-73. 